\title{
Correlation Between Indicators of Intestinal Environment and Amount of Carbon Dioxide in Gas Excreted During Defecation
}

\author{
Kazuhiro HiRAYAma ${ }^{*}$, Hiroshi Hashimoto ${ }^{2}$, Akemi TAKeshita ${ }^{2}$, Changsheng Rui², \\ Satoko NogUCHI ${ }^{2}$, Yoshinori TAKEZAKI ${ }^{2}$ and Kikuji ITOH ${ }^{1}$ \\ ${ }^{1}$ Laboratory of Veterinary Public Health, Graduate School of Agricultural and Life Sciences, The University of Tokyo, Bunkyo, Tokyo \\ 113-8657, Japan \\ 2 Sensing Technology Research Group, Kokura Department, Research Laboratory, TOTO Ltd., 2-1-1 Nakashima, Kokurakita-ku, \\ Kitakyushu-city, Fukuoka 802-8601, Japan
}

Received October 14, 2009; Accepted March 3, 2010

\begin{abstract}
Intestinal microbiota have marked metabolic activity and influences the host in both beneficial and harmful ways. In the present study, we developed an apparatus to measure the amount of $\mathrm{CO}_{2}$ in the gas excreted during defecation and investigated whether this amount of $\mathrm{CO}_{2}$ can be used as an indicator of the intestinal environment. The apparatus consists of a fan and a commercial $\mathrm{CO}_{2}$ sensor attached to a toilet stool. Fecal pH, fecal water content, concentrations of short chain organic acids (SCFAs) and intestinal putrefactive products and composition of fecal microbiota were analyzed as indicators of the intestinal environment. The apparatus could measure the amount of $\mathrm{CO}_{2}$ in the gas with good reproducibility, irrespective of the open area at the top of the toilet stool, position of gas injection and composition of the gas. In a volunteer study, the amount of $\mathrm{CO}_{2}$ in defecation gas correlated with $\mathrm{pH}$, water content and concentrations of SCFAs and intestinal putrefactive products in the feces, although correlation with the composition of intestinal microbiota was not be observed. The results indicate that the amount of $\mathrm{CO}_{2}$ in defecation gas can be measured with simple and sanitary procedures and is a good indicator of the intestinal environment.
\end{abstract}

Key words: $\mathrm{CO}_{2}$; defecation gas; fecal water content; putrefactive products; short chain fatty acids

\section{INTRODUCTION}

About $10^{14}$ bacteria in total colonize the human intestine and have strong metabolic activities overwhelming the activities of the host itself (5). As a result of this active metabolism, microbiota are able to produce a wide range of compounds that have both beneficial and harmful effects on gut physiology as well as systemic influences. For instance, colonic bacteria produce short-chain fatty acids (SCFAs) through which the host may salvage energy from undigested carbohydrates and proteins $(2,3,16)$. On the other hand, intestinal microbiota produces harmful metabolites including intestinal putrefactive products and carcinogens. Intestinal microbiota also deconjugate conjugated bile acids and convert primary bile acids to secondary bile acids, which show tumor promoter activity. Thus the metabolic activities of intestinal microbiota affect the health and diseases of the host (13). Therefore, it is important to maintain the composition and metabolic activities of the intestinal microbiota in a

*Corresponding author. Mailing address: Laboratory of Veterinary Public Health, Department of Veterinary Medical Science, Graduate School of Agricultural and Life Sciences, The University of Tokyo, Bunkyo, Tokyo 113-8657, Japan. Phone: +81-3-5841-3094.

Fax: +81-3-5841-8188. E-mail: akazu@mail.ecc.u-tokyo.ac.jp healthy condition. However, a great deal of effort is required to analyze and monitor the intestinal environment.

In the present study, we developed an apparatus for analyzeing the composition of the gas components that are excreted during defecation and investigated whether the defecation gas composition can be used as an indicator for the intestinal environment. $\mathrm{CO}_{2}$ was selected as the measured gas component, because it is excreted by every individual and sensors with sufficient specificity and sensitivity are commercially available. As indicators of intestinal environment, $\mathrm{pH}$, water content, concentrations of short chain organic acids and intestinal putrefactive products and composition of fecal microbiota were analyzed, and their correlations with the amount of $\mathrm{CO}_{2}$ in defecation gas were investigated.

\section{MATERIALS AND METHODS}

Apparatus for the measurement of $\mathrm{CO}_{2}$ in defecation gas

Air in the toilet stool was removed with a fan $(90 \mathrm{l} / \mathrm{min})$ and passed through a commercial $\mathrm{CO}_{2}$ sensor which measures $\mathrm{CO}_{2}$ using a non-dispersive infra-red (NDIR) technique $\left(\mathrm{CO}_{2}\right.$ EngineK30, SenseAir AB, Sweden) (Fig. 1). The concentration of $\mathrm{CO}_{2}$ was measured and the peak value of the output from the sensor was recorded as the 


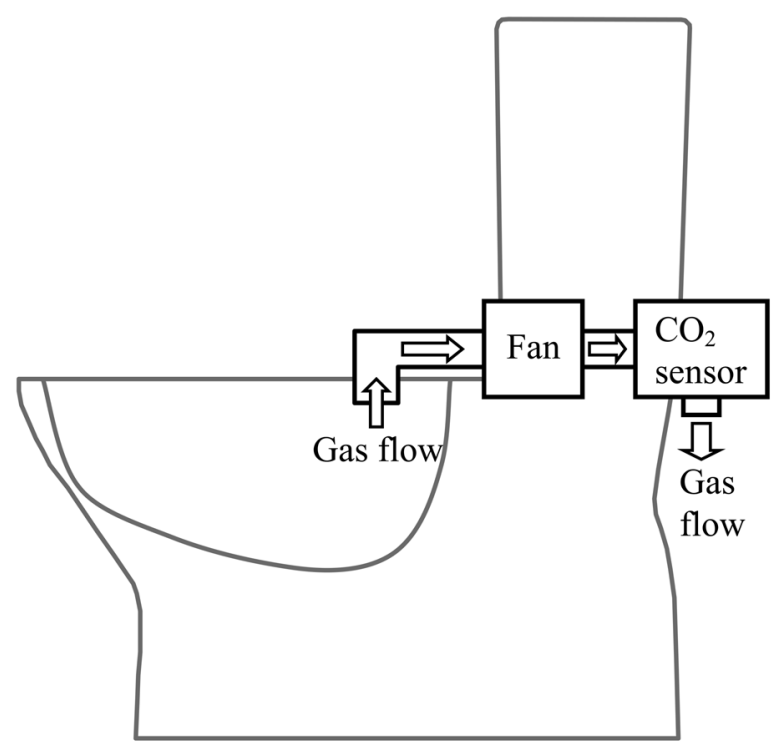

Fig. 1. Apparatus for measuring the amount of $\mathrm{CO}_{2}$ in gas excreted during defecation. Air in the toilet stool was removed with a fan $(90 \mathrm{l} / \mathrm{min})$ and passed through a commercial $\mathrm{CO}_{2}$ sensor which uses a non-dispersive infrared technique to measure $\mathrm{CO}_{2}$ in the air flow.

amount of $\mathrm{CO}_{2}$ in defecation gas.

\section{Confirmation of the specificity of the sensor}

A gas mixture consisting of 3,500 ppm $\mathrm{CO}_{2}$ and other components at different concentrations in $\mathrm{N}_{2}$ gas was introduced at a flow rate of $10 \mathrm{l} / \mathrm{min}$ into a flow cell within which the $\mathrm{CO}_{2}$ sensor was set, and the $\mathrm{CO}_{2}$ sensor output was observed. The other gas components were $\mathrm{H}_{2}, \mathrm{NH}_{3}$ or $\mathrm{H}_{2} \mathrm{~S}$ at a concentration of $50-500,5-50$ or $5-50 \mathrm{ppm}$, respectively.
Evaluation of the effects of the open space at the top of the toilet stool and gas excretion position

To evaluate the efficacy of gas collection and the effects of the body habitus and position of subjects during defecation, the $\mathrm{CO}_{2}$ concentration was measured with different open areas at the top of the toilet stool and positions of gas injection. The conditions tested are listed in Table 1. The injected gas composition was $15 \%$ of $\mathrm{CO}_{2}$ in $\mathrm{N}_{2}$ and 0.31 of the mixed gas was injected in 2 seconds. When the mixed gas was injected at $7.25 \mathrm{~cm}$ from the posterior side, the open areas at the front, representing the space between the legs, were 0,41 or $92 \mathrm{~cm}^{2}$ and the open area at the rear, representing space behind the body, were 0,11 or $29 \mathrm{~cm}^{2}$. When the open area at the front was 92 $\mathrm{cm}^{2}$ and that at the rear was $11 \mathrm{~cm}^{2}$, the mixed gas was also injected at 10.5 and $13.75 \mathrm{~cm}$ from the posterior side. The measurements were repeated five times. The $\mathrm{CO}_{2}$ concentration was also measured when the open area at the top of the toilet stool $\left(450 \mathrm{~cm}^{2}\right)$ was not covered at all.

\section{Confirmation of linearity of the $\mathrm{CO}_{2}$ sensor output}

The linearity of the $\mathrm{CO}_{2}$ sensor output was investigated when the constant amount $(0.31)$ of mixed gases with different $\mathrm{CO}_{2}$ concentrations $(5,10,15$ and $20 \%$ ) were injected into the toilet stool. $\mathrm{CO}_{2}$ sensor output was also investigated when different amounts of mixed gas $(0.1$, 0.3 and $0.5 \mathrm{l}$ ) with a fixed $\mathrm{CO}_{2}$ concentration $(15 \%)$ were injected. The open area was $92 \mathrm{~cm}^{2}$ at the front and $0 \mathrm{~cm}^{2}$ at the rear. The mixed gases were injected at $7.25 \mathrm{~cm}$ from the posterior side in 2 seconds.

\section{Subjects}

Ten healthy volunteers, aged 25 to 48 years, were thoroughly informed about the aim and procedure of the experiment. The Ethical Committee of TOTO Ltd. approved the experimental protocol. After 2 weeks of

Table 1. Influence of different open areas at the top of the toilet stool and positions of gas injection on $\mathrm{CO}_{2}$ sensor output

\begin{tabular}{ccccc}
\hline $\begin{array}{c}\text { Position of gas } \\
\text { injection from the } \\
\text { posterior side }(\mathrm{cm})\end{array}$ & $\begin{array}{c}\text { Open area at rear } \\
\left(\mathrm{cm}^{2}\right)\end{array}$ & $\begin{array}{c}\text { Open area at front } \\
\left(\mathrm{cm}^{2}\right)\end{array}$ & $\begin{array}{c}\text { Mean of sensor } \\
\text { output }(\mathrm{ppm})\end{array}$ & CV value (\%) \\
\hline 7.25 & Open $^{\mathrm{a}}$ & Open & 1675 & 2.8 \\
7.25 & 29 & 92 & 1740 & 5.9 \\
7.25 & 11 & 92 & 1656 & 6.0 \\
7.25 & 0 & 92 & 1728 & 3.2 \\
7.25 & 0 & 41 & 1614 & 3.2 \\
7.25 & 0 & 0 & 1548 & 2.3 \\
10.50 & 11 & 92 & 1737 & 4.5 \\
13.75 & 11 & 92 & 1784 & 4.1 \\
\hline
\end{tabular}

a: Open area at the top of the toilet stool $\left(450 \mathrm{~cm}^{2}\right)$ was not covered at all. 
usual life without any dietary restriction, the volunteers were given $250 \mathrm{~g}$ /day of commercial yoghurt (Meiji Bulgaria Yoghurt, Meiji Dairies Co., Ltd., Tokyo) for 2 weeks to manipulate the intestinal environment. In addition to yoghurt, the subjects were then given $40 \mathrm{~g} /$ day of cereal (All-Bran ${ }^{\circledR}$, Kellogg (Japan) K. K., Tokyo) and $16 \mathrm{~g} /$ day of commercial oligosaccharides (Oligono Okage $^{\circledR}$, Ensuiko Sugar Refining Co., Ltd., Tokyo) for another 2 weeks. Feces were collected on a tray placed above the water surface in the toilet stool at each defecation during the experimental period and the amount of $\mathrm{CO}_{2}$ in defecation gas and fecal $\mathrm{pH}$ were measured by the volunteers themselves. In addition to these measurements, fecal samples were collected into a container (a capacity of 1.21 , about $9 \mathrm{~cm}$ in height) instead of a tray at weeks 2 and 6 of the experiment, and transported anaerobically with AnaeroPack-Anaero ${ }^{\circledR}$ (Mitsubishi Gas Chemical Co., Inc., Tokyo) on ice to a laboratory at The University of Tokyo for analysis of indicators of the intestinal environment.

\section{Analysis of feces as an indicator of intestinal conditions}

Fecal $\mathrm{pH}$ was measured with a $\mathrm{pH}$ meter (D-51, Horiba Ltd., Kyoto) by placing an electrode (type 6252, Horiba Ltd.) in the feces. The measurements were repeated three times at different locations of the feces and the average of the values was recorded as fecal $\mathrm{pH}$. The composition of the fecal microbiota was analyzed immediately after receiving the samples and the samples were stored at $-80^{\circ} \mathrm{C}$ until used in other analyses. Fecal water content was calculated from the difference of the weight before and after overnight freeze-drying. The composition of fecal microbiota was analyzed by the culture method described previously (8). The concentration of fecal SCFAs was measured by the post-column method (15) with HPLC and the concentration of intestinal putrefactive products was measured with HPLC (9).

\section{Statistical analysis}

Correlations and the significance of the correlations were calculated with Microsoft ${ }^{\circledR}$ Office Excel 2003.

\section{RESULTS}

Basic data of the apparatus for measurement of $\mathrm{CO}_{2}$ in defecation gas

The $\mathrm{CO}_{2}$ sensor output was not affected by the addition of $\mathrm{H}_{2}, \mathrm{NH}_{3}$ or $\mathrm{H}_{2} \mathrm{~S}$ to the mixture of $\mathrm{N}_{2}$ and $\mathrm{CO}_{2}$ (Fig. 2). Outputs of the $\mathrm{CO}_{2}$ sensor with different open areas at the top of the toilet stool and different positions of gas injection are shown in Table 1 . In all conditions tested, the coefficient of variation ( $\mathrm{CV}$ value) of the outputs of

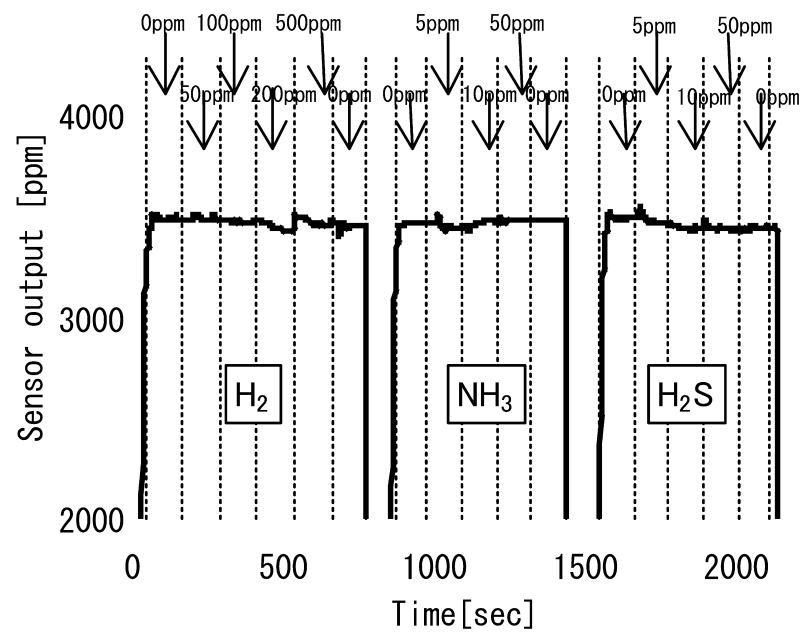

Fig. 2. Effects of $\mathrm{H}_{2}, \mathrm{NH}_{3}$ or $\mathrm{H}_{2} \mathrm{~S}$ added to the mixed gas of $\mathrm{N}_{2}$ and $\mathrm{CO}_{2}$ on $\mathrm{CO}_{2}$ sensor output. A gas mixture consisting of $3,500 \mathrm{ppm} \mathrm{CO}_{2}$ and one other component gas with different concentrations in $\mathrm{N}_{2}$ gas was introduced at a flow rate of 10 1/ min into a flow cell within which the $\mathrm{CO}_{2}$ sensor was set, and the $\mathrm{CO}_{2}$ sensor output was observed. The other component gases were $\mathrm{H}_{2}, \mathrm{NH}_{3}$ and $\mathrm{H}_{2} \mathrm{~S}$, and their concentrations were $50-500,5-50$ and 5-50 ppm, respectively.

five repeated measurements was less than $6 \%$. The CV value of all recorded outputs with different open areas and injection positions was $5.8 \%$. The concentration of $\mathrm{CO}_{2}$ in the mixed gases correlated well with the $\mathrm{CO}_{2}$ sensor output ( $\mathrm{r}=0.999)$ and the amount of mixed gas also correlated well with the $\mathrm{CO}_{2}$ sensor output $(\mathrm{r}=0.999)$ (Fig. 3).

Correlation between the amount of $\mathrm{CO}_{2}$ in defecation gas and fecal $\mathrm{pH}$

The amount of $\mathrm{CO}_{2}$ in defecation gas and fecal $\mathrm{pH}$ were both measured throughout the experimental period, and the correlation between the amount of $\mathrm{CO}_{2}$ and fecal $\mathrm{pH}$ was investigated (Fig. 4). There was a negative correlation between the amount of $\mathrm{CO}_{2}$ and fecal $\mathrm{pH}(\mathrm{r}=$ $-0.550)$.

Correlation between $\mathrm{CO}_{2}$ in defecation gas and indicators of the intestinal environment

The amount of $\mathrm{CO}_{2}$ in defecation gas and various parameters of the intestinal environment, before and after ingestion of yoghurt, cereal and oligosaccharides, are shown in Tables 2 and 3. All of the parameters investigated were not significantly affected by the intake of these dietary factors. The correlations between the amount of $\mathrm{CO}_{2}$ and parameters of the intestinal environment were calculated for all fecal samples 
A

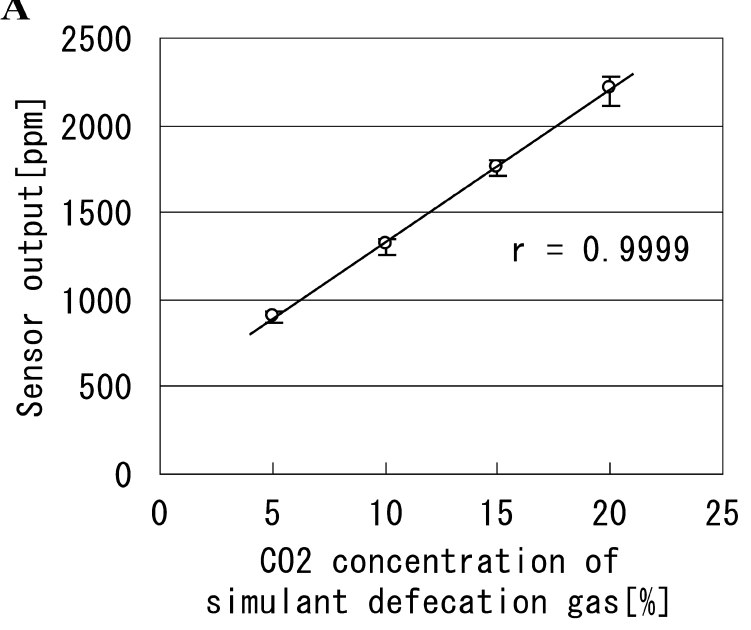

B

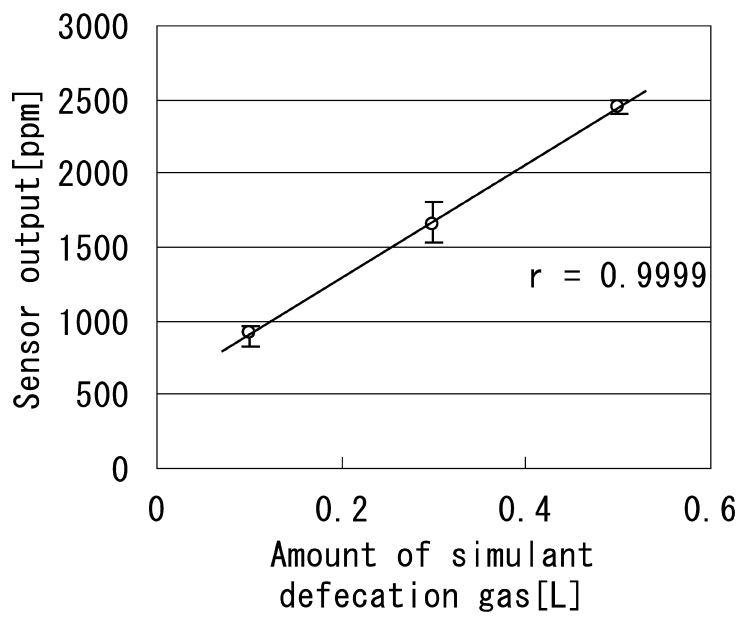

Fig. 3. Effects of concentration of $\mathrm{CO}_{2}$ in mixed gas and amount of mixed gas on $\mathrm{CO}_{2}$ sensor output. A) $\mathrm{CO}_{2}$ was mixed with $\mathrm{N}_{2}$ at a concentration of $5,10,15$ or $20 \%$, and a constant volume (0.3 1) was injected into the stool. B) $\mathrm{CO}_{2}$ was mixed with $\mathrm{N}_{2}$ at a concentration of $15 \%$ and $0.1,0.3$ or 0.51 of the mixed gas was injected into stool. The open area was $92 \mathrm{~cm}^{2}$ at the front and $0 \mathrm{~cm}^{2}$ at the rear. The mixed gases were injected at $7.25 \mathrm{~cm}$ from the posterior side in 2 seconds.

obtained. Fecal water content and the amount of $\mathrm{CO}_{2}$ in the defecation gas showed a strong and significant positive correlation $(\mathrm{r}=0.754)$ and fecal concentration of acetic acid also showed a significant positive correlation with the amount of $\mathrm{CO}_{2}$. The concentration of total SCFAs was also positively correlated with the amount of $\mathrm{CO}_{2}$, whereas the concentrations of total intestinal putrefactive products, $i$-butyric acid and $i$-valeric acid, showed negative correlations with the amount of $\mathrm{CO}_{2}$, although the correlations were not statistically significant (Table 4).

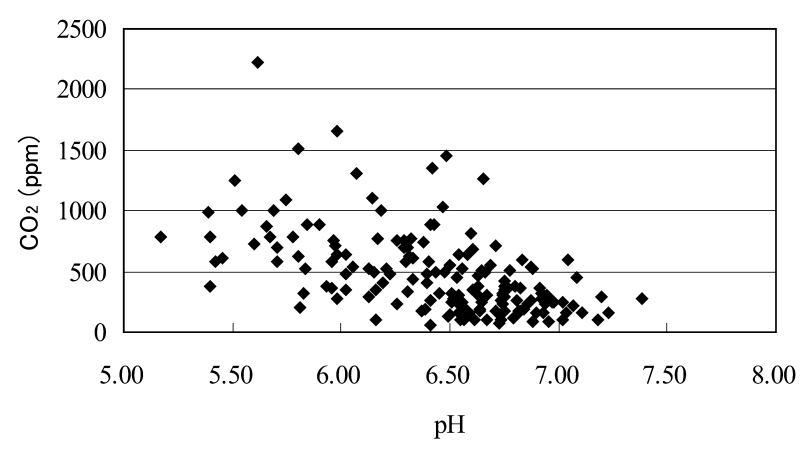

Fig. 4. Correlation between the amount of $\mathrm{CO}_{2}$ in defecation gas and fecal $\mathrm{pH}$. The correlation between the amount of $\mathrm{CO}_{2}$ and fecal $\mathrm{pH}$ was analyzed when measurement of both the amount of $\mathrm{CO}_{2}$ in defecation gas and fecal $\mathrm{pH}$ were both possible during the experimental period.

Table 2. Amount of $\mathrm{CO}_{2}$ in defecation gas, fecal $\mathrm{pH}$, fecal water content and composition of fecal microbiota before and after ingestion of yoghurt, cereal and oligosaccharides $(\mathrm{n}=10)$

\begin{tabular}{lrr}
\hline & Before & After \\
\hline (ppm) & & \\
$\mathrm{CO}_{2}$ (at fecal sampling) & $263 \pm 232^{\mathrm{a}}$ & $287 \pm 172$ \\
$\mathrm{CO}_{2}$ (immediately & $484 \pm 232$ & $476 \pm 341$ \\
$\quad$ before fecal sampling) & & \\
$\mathrm{pH}$ & $6.27 \pm 0.41$ & $6.43 \pm 0.50$ \\
Water (\%) & $76.5 \pm 6.1$ & $78.8 \pm 5.8$ \\
(log 10 g) & & \\
Total bacteria & $10.3 \pm 0.5$ & $10.6 \pm 0.5$ \\
Bacteroidaceae & $9.8 \pm 0.9(10) \mathrm{b}$ & $10.2 \pm 0.6(10)$ \\
Bifidobacteria & $9.6 \pm 0.4(10)$ & $9.9 \pm 0.7(10)$ \\
Eubacteria & $9.7 \pm 0.4(10)$ & $9.8 \pm 1.0(10)$ \\
Clostridia & $8.6 \pm 0.8(10)$ & $8.9 \pm 0.9(10)$ \\
Veillonellaceae & $4.9 \pm 1.3(6)$ & $6.9 \pm 2.3(6)$ \\
Lactobacilli & $5.7 \pm 2.0(7)$ & $5.5 \pm 1.7(7)$ \\
Enterobacteriaceae & $6.4 \pm 1.7(7)$ & $6.1 \pm 1.6(9)$ \\
Streptococci & $7.4 \pm 1.5(10)$ & $7.8 \pm 1.2(10)$ \\
Direct microscopic count & $11.2 \pm 0.2$ & $11.2 \pm 0.4$ \\
\hline
\end{tabular}

a: Mean \pm SD

b: Number detected.

The amount of $\mathrm{CO}_{2}$ in the defecation gas might not have been measured correctly in some cases because of disturbance to air flow caused by the container used for fecal sampling. Accordingly, correlations between the intestinal environment and the amount of $\mathrm{CO}_{2}$ at defecation immediately before the collection of feces were also analyzed. The amount of $\mathrm{CO}_{2}$ at defecation immediately before the collection of feces showed a strong and significant negative correlation with fecal $\mathrm{pH}$ $(r=-0.720)$ and significant negative correlations with concentrations of total intestinal putrefactive products, 
Table 3. Concentrations of fecal SCFAs and intestinal putrefactive products before and after ingestion of yoghurt, cereal and oligosaccharides $(n=10)$

\begin{tabular}{lcr}
\hline & Before & After \\
\hline$(\mu$ mol/g) & & \\
Total organic acids & $132.1 \pm 28.0^{\mathrm{a}}$ & $130.5 \pm 34.7$ \\
Formate & $1.2 \pm 0.5$ & $0.1 \pm 0.2$ \\
Acetate & $69.7 \pm 17.6$ & $67.8 \pm 19.4$ \\
Propionate & $32.3 \pm 9.2$ & $29.3 \pm 10.0$ \\
$i$-Butyrate & $1.7 \pm 0.9$ & $1.9 \pm 1.2$ \\
$n$-Butyrate & $17.6 \pm 3.8$ & $17.8 \pm 8.2$ \\
$i$-Valerate & $2.3 \pm 2.0$ & $2.4 \pm 1.7$ \\
$n$-Valerate & $3.2 \pm 1.6$ & $3.4 \pm 2.2$ \\
Succinate & $4.2 \pm 7.7$ & $7.7 \pm 18.1$ \\
Lactate & $0.0 \pm 0.0$ & $0.1 \pm 0.2$ \\
$(\mu \mathrm{g} / \mathrm{g})$ & & \\
Total putrefactive products & $75.5 \pm 39.7$ & $63.3 \pm 40.5$ \\
Phenol & $7.0 \pm 13.0$ & $2.7 \pm 5.4$ \\
Cresol & $38.9 \pm 29.8$ & $29.2 \pm 24.5$ \\
Indole & $27.4 \pm 11.8$ & $28.0 \pm 14.2$ \\
Skatole & $2.3 \pm 4.4$ & $3.4 \pm 5.8$ \\
\hline
\end{tabular}

a: Mean \pm SD

indole, $p$-cresol and $i$-valeric acid $(\mathrm{r}=-0.692,-0.660$, -0.490 and -0.619 , respectively), and significant positive correlations with fecal water contents and concentrations of total SCFAs, acetic acid and lactic acid $(\mathrm{r}=0.550$, $0.485,0.594$ and 0.449 , respectively) were observed (Table 4). Significant negative correlations were also observed with direct microscopic counts $(\mathrm{r}=-0.449)$ (Table 4). The amounts of $\mathrm{CO}_{2}$ measured at defecation immediately before fecal collection and at fecal collection showed a significant positive correlation $(\mathrm{r}=$ $0.490)$.

\section{DISCUSSION}

Intestinal microbiota have marked metabolic activity and their metabolism influences the health and diseases of the host in both beneficial and harmful ways. Nutrients that pass undigested from the small intestine into the large intestine are fermented by colonic bacteria. Fermentation products include SCFAs, intestinal putrefactive products and gases, e.g. carbon dioxide, methane and hydrogen $(1$, $4,5)$. SCFAs are absorbed and utilized as an energy source by the host or directly by colonic epithelial cells (12). SCFAs also influence the metabolism and growth of endogenous and exogenous bacteria by reducing the $\mathrm{pH}$ of intestinal contents $(5,14)$. Intestinal microbiota also produce metabolites harmful to the host's health. For example, metabolites produced by intestinal bacteria from amino acids, including indole, phenol and $p$-cresol, are thought to relate to carcinogenesis $(23,24)$. It is
Table 4. Correlations between the amounts of $\mathrm{CO}_{2}$ in defecation gas at fecal sampling or at defecation immediately before fecal sampling and fecal $\mathrm{pH}$, fecal water content, composition of fecal microbiota and concentrations of fecal SCFAs and intestinal putrefactive products in fecal samples from 10 healthy volunteers

\begin{tabular}{|c|c|c|}
\hline & $\begin{array}{c}\mathrm{CO}_{2} \text { at fecal } \\
\text { sampling }\end{array}$ & $\begin{array}{c}\mathrm{CO}_{2} \text { at defecation } \\
\text { immediately before } \\
\text { fecal sampling }\end{array}$ \\
\hline $\begin{array}{l}\mathrm{CO}_{2} \text { at defecation immediately } \\
\text { before fecal sampling }\end{array}$ & $0.490 *$ & \\
\hline $\mathrm{pH}$ & -0.329 & $-0.720 * * *$ \\
\hline Water $(\%)$ & $0.754 * * *$ & $0.550 *$ \\
\hline Total bacteria & -0.145 & -0.376 \\
\hline Bacteroidaceae & 0.013 & -0.270 \\
\hline Bifidobacteria & -0.144 & -0.174 \\
\hline Eubacteria & -0.254 & -0.428 \\
\hline Clostridia & 0.261 & 0.131 \\
\hline Veillonellaceae & 0.185 & 0.038 \\
\hline Lactobacilli & -0.156 & 0.232 \\
\hline Enterobacteriaceae & 0.265 & 0.225 \\
\hline Streptococci & 0.216 & 0.052 \\
\hline Direct count & -0.263 & $-0.449 *$ \\
\hline Total organic acids & 0.417 & $0.485 *$ \\
\hline Formate & -0.073 & -0.146 \\
\hline Acetate & $0.546 *$ & $0.594 * *$ \\
\hline Propionate & 0.015 & 0.127 \\
\hline$i$-Butyrate & -0.425 & -0.407 \\
\hline Butyrate & 0.320 & 0.333 \\
\hline$i$-Valerate & -0.433 & $-0.619 * *$ \\
\hline Valerate & -0.101 & -0.344 \\
\hline Succinate & 0.154 & 0.223 \\
\hline Lactate & 0.241 & $0.449 *$ \\
\hline Total putrefactive products & -0.402 & $-0.692 * * *$ \\
\hline Phenol & -0.281 & -0.156 \\
\hline Cresol & -0.308 & $-0.660 * *$ \\
\hline Indole & -0.262 & $-0.490 *$ \\
\hline Skatole & -0.255 & -0.344 \\
\hline
\end{tabular}

$* p<0.05 ; * * p<0.01 ; * * * p<0.001$

reported that the production of these intestinal putrefactive products are significantly reduced by ingestion of probiotics and prebiotics $(5,18)$. Probiotic bacteria or indigenous bifidobacteria are stimulated by probiotics and prebiotics produce SCFAs as their metabolic products and these SCFAs reduce the intestinal $\mathrm{pH}$. A low $\mathrm{pH}$ environment is considered to suppress the proliferation of harmful bacteria and to inhibit the production of putrefactive products $(5-7,19,21)$.

In the present study, fecal $\mathrm{pH}$ showed strong negative correlations with total SCFAs and acetic acid concentration ( $\mathrm{r}=-0.713$ and -0.728 , respectively) and negative correlations with propionic and n-butyric acid concentrations ( $\mathrm{r}=-0.467$ and -0.511 , respectively), as well as positive correlations with $i$-valeric acid, total 
putrefactive products and $p$-cresol concentrations $(\mathrm{r}=$ $0.547,0.594$ and 0.583 , respectively) (data not shown). Our results are in basic agreement with those of a previous study (10) in respect of the relationships among fecal $\mathrm{pH}$, water content, SCFAs concentration and concentrations of intestinal putrefactive products. On the other hand, we did not find any significant changes in the amount of $\mathrm{CO}_{2}$ and indicators of intestinal environment in response to dietary manipulation. A better controlled study will be needed to investigate the effects of pro- and prebiotics on defecation gas and intestinal environment.

Intestinal microbiota have an active role in carcinogenesis via conversion of bile acids to secondary bile acids, more active tumor promoters, and the suppression of this conversion would be beneficial for the prevention of colorectal cancer (11). It is thought that the production of SCFAs and the reduction of $\mathrm{pH}$ by intestinal microbiota may suppress the conversion of bile acids to secondary bile acids $(17,20)$. Epidemiological studies have also reported that increase of intestinal $\mathrm{pH}$ is correlated with colon cancer risk (22).

It is important to maintain the composition and metabolic activities of the intestinal microbiota in a healthy condition for health and prevention of diseases. Regular monitoring of the intestinal environment is useful for understanding and improving the intestinal environment through dietary habits and lifestyles. However, it is quite difficult and requires a great deal of work to directly analyze and monitor environmental conditions in the intestine. Even measurement of fecal $\mathrm{pH}$, one of the easiest methods, causes sanitary and psychological problems based on collection and handling of fecal samples. In the present study, we employed gas, which is excreted at each defecation and can be collected without any contact with feces, as a parameter of the intestinal environment. Because carbohydrates in the large intestine are fermented by bacteria to form organic acids and gases including carbon dioxide, hydrogen and methane $(1,4,5)$, we performed a preliminary analysis of carbon dioxide, hydrogen and methane for which sensors are commercially available. Based on the results of the preliminary analysis, an apparatus for the measurement of $\mathrm{CO}_{2}$ in defecation gas was prepared, because $\mathrm{CO}_{2}$ was excreted by all the subjects tested and the sensitivity and specificity of the sensor was sufficient. On the other hand, $\mathrm{H}_{2}$ showed large inter-individual differences of concentration and was not excreted by some subjects and the sensor for methane had a specificity problem.

The results indicate that the apparatus used in the present study is able to measure the amount of $\mathrm{CO}_{2}$ in defecation gas with good reproducibility, irrespective of body position and body habitus of the subjects, and the presence of other gases in defecation gas (Table 1 and Figs. 2 and 3). The amount of $\mathrm{CO}_{2}$ in defecation gas was measured by the apparatus and showed a negative correlation with fecal $\mathrm{pH}$ under experimental conditions with human volunteers (Fig. 4). The correlations between the amount of $\mathrm{CO}_{2}$ in defecation gas and indicators of intestinal environment were further investigated and the amount of $\mathrm{CO}_{2}$ measured was found to correlate with $\mathrm{pH}$, water content, concentrations of SCFAs and intestinal putrefactive products of the feces (Table 4). Our results indicate that the apparatus used in the present study can measure the amount of $\mathrm{CO}_{2}$ in defecation gas with easy and sanitary procedures, and also that the amount of $\mathrm{CO}_{2}$ in defecation gas measured by the apparatus is a good indicator of the intestinal environment, although no correlation between the amount of $\mathrm{CO}_{2}$ in defecation gas and the composition of intestinal microbiota was found. These results suggest that the metabolism of intestinal microbiota can be modified without significant changes in composition. It is possible that a more detailed bacteriological investigation including molecular techniques would reveal a correlation between the amount of $\mathrm{CO}_{2}$ in defecation gas and the composition of intestinal microbiota.

The amount of $\mathrm{CO}_{2}$ at defecation immediately before the collection of feces correlated well with the indicators of intestinal environment, while the amount of $\mathrm{CO}_{2}$ measured at fecal collection showed fewer significant correlations. This is probably because the air flow in the toilet stool was disturbed by the container for fecal sampling used instead of the tray. However, the amount of $\mathrm{CO}_{2}$ measured at defecation immediately before fecal collection significantly correlated with that measured at fecal collection. This result indicates that the intestinal environment is quite stable in the same individual over a short period of time and suggests that the amount of $\mathrm{CO}_{2}$ in defecation gas is a good indicator of the intestinal environment.

In conclusion, the apparatus used in this study would be very useful for regular monitoring of the intestinal environment. Further studies with various types of subjects, e.g. subjects with abnormal intestinal environments, such as diarrhea and constipation, should be performed for evaluation of this apparatus.

\section{REFERENCES}

(1) Christian MT, Edwards CA, Preston T, Johnston L, Varley R, Weaver LT. 2003. Starch fermentation by faecal bacteria of infants, toddlers and adults: importance for energy salvage. Eur J Clin Nutr 57: 
1486-1491.

(2) Cummings JH. 1981. Short chain fatty acids in the human colon. Gut 22: 763-779.

(3) Cummings JH, Macfarlane GT. 1991. A review: the control and consequences of bacterial fermentation in the human colon. J Appl Bacteriol 70: 443-159.

(4) Cummings JH, Macfarlane GT. 1997. Role of intestinal bacteria in nutrient metabolism. J Parenteral Enteral Nutr 21:357-365.

(5) Gibson GR, Roberfroid MB. 1995. Dietary modulation of the human colonic microbiota: introducing the concept of prebiotics. J Nutr 125: 1401-1412.

(6) Gibson GR, Wang X. 1994. Regulatory effects of bifidobacteria on the growth of other colonic bacteria. J Appl Bacteriol 77: 412-420.

(7) Gilliland SE. 1990. Health and nutritional benefits from lactic acid bacteria. FEMS Microbiol Rev 87: 175-188.

(8) Hirayama K, Itoh K, Takahashi E, Mitsuoka T. 1995. Comparison of composition of faecal microbiota and metabolism of faecal bacteria among 'human-floraassociated' mice inoculated with faeces from six different human donors. Microb Ecol Health Dis 8: 199-211.

(9) Hirayama K, Kouno J, Itoh K, Matsumoto K. 2003. Abnormal intestinal environment in rats with spontaneous eosinophilia (MES rat): A possible new model for studying intestinal putrefaction. Microb Ecol Health Dis 15: 57-62.

(10) Ikeda N, Saito Y, Shimizu J, Ochi A, Mizutani J, Watabe J. 1994. Variations in concentrations of bacterial metabolites, enzyme activities, moisture, $\mathrm{pH}$ and bacterial composition between and within individuals in faeces of seven healthy adults. J Appl Bacteriol 77: 185-194.

(11) Klurfeld DM. 1992. Dietary fiber-mediated mechanisms in carcinogenesis. Cancer Res 52: 2055S2059S.

(12) Knudsen KEB, Serena A, Canibe N, Juntunen KS. 2003. New insight into butyrate metabolism. Proc Nutr Soc 62: 81-86.

(13) Mitsuoka T. 2002. Prebiotics and intestinal flora. Biosci Microflora 21: 3-12.

(14) Modler HW, McKellar RC, Yaguchi M. 1990.
Bifidobacteria and bifidogenic factors. Can Inst Food Sci Technol J 23: 29-41.

(15) Ohmomo S, Tanaka O, Kuze-Kitamoto H. 1993. Analysis of organic acids in silage by highperformance liquid chromatography. Bull Natl Grassland Res Inst 48: 51-56.

(16) Rerat A, Fiszlewick M, Giusi A, Vaugeland P. 1986. Influence of meal frequency on postprandial variation in the production and absorption of volatile fatty acids in the digestive tract of conscious pigs. J Anim Sci 64: 448-456.

(17) Ridlon JM, Kang D-J, Hylemon PB. 2006. Bile salt biotransformations by human intestinal bacteria. $\mathrm{J}$ Lipid Res 47: 241-259.

(18) Shioiri T, Yahagi K, Nakayama S, Asahara T, Yuki N, Kawakami K, Yamaoka Y, Sakai Y, Nomoto K, Totani M. 2006. The effects of a symbiotic fermented milk beverage containing Lactobacillus casei strain Shirota and transgalactosylated oligosaccharides on defecation frequency, intestinal microflora, organic acid concentrations, and putrefactive metabolites of suboptimal health state volunteers: A randomized placebocontrolled cross-over study. Biosci Microflora 25: 137-146.

(19) Smith EA, Macfarlane GT. 1996. Enumeration of human colonic bacteria producing phenolic and indolic compounds: effect of $\mathrm{pH}$, carbohydrate availability and retention time on dissimilatory aromatic amino acid metabolism. J Appl Bacteriol 81: 288-302.

(20) Van Munster IP, Nagengast FM. 1993. The role of carbohydrate fermentation in colon cancer prevention. Scand J Gastroenterol Suppl 200: 80-86.

(21) Vince AJ, Burridge SM. 1980. Ammonia production by intestinal bacteria: the effects of lactose and glucose. J Med Microb 13: 177-191.

(22) Walker ARP, Walker BF, Walker AJ. 1986. Fecal pH, dietary fiber intake, and proneness to colon cancer in 4 South-African populations. Br J Cancer 53: 489-495.

(23) Wynder EL, Hoffmann D. 1968. Experimental tobacco carcinogenesis. Science 162: 862-871.

(24) Boutwell RK, Bosch DK. 1959. The tumor promoting action of phenol and related compounds for mouse skin. Cancer Res 19: 413-424. 